\title{
Chlorophyll Dispersal by Eddy-Eddy Interactions in the Gulf of Mexico
}

\author{
M. Toner \\ University of Delaware
}

A. D. Kirwan

University of Delaware

A. C. Poje

University of New York

L. H. Kantha

University of Colorado

Frank E. Muller-Karger

University of South Florida, carib@usf.edu

See next page for additional authors

Follow this and additional works at: https://scholarcommons.usf.edu/msc_facpub

Part of the Marine Biology Commons

\section{Scholar Commons Citation}

Toner, M.; Kirwan, A. D.; Poje, A. C.; Kantha, L. H.; Muller-Karger, Frank E.; and Jones, C. K. R. T., "Chlorophyll Dispersal by Eddy-Eddy Interactions in the Gulf of Mexico" (2003). Marine Science Faculty Publications. 57.

https://scholarcommons.usf.edu/msc_facpub/57

This Article is brought to you for free and open access by the College of Marine Science at Scholar Commons. It has been accepted for inclusion in Marine Science Faculty Publications by an authorized administrator of Scholar Commons. For more information, please contact scholarcommons@usf.edu. 
Authors

M. Toner, A. D. Kirwan, A. C. Poje, L. H. Kantha, Frank E. Muller-Karger, and C. K. R. T. Jones 


\title{
Chlorophyll dispersal by eddy-eddy interactions in the Gulf of Mexico
}

\author{
M. Toner, ${ }^{1}$ A. D. Kirwan Jr., ${ }^{1}$ A. C. Poje, ${ }^{2}$ L. H. Kantha, ${ }^{3}$ F. E. Müller-Karger, ${ }^{4}$ \\ and C. K. R. T. Jones ${ }^{5}$ \\ Received 3 June 2002; revised 15 October 2002; accepted 11 November 2002; published 1 April 2003.
}

[1] A Lagrangian analysis of the transport and dispersal of plumes observed in satellitederived ocean color images was conducted using a data-assimilating model of the Gulf of Mexico. The interaction between pervasive cyclonic and anticyclonic eddies in the Gulf generated advective paths that connect remote shelf regions. These paths aligned remarkably well with the plume events recorded with the chlorophyll-a ocean color product from SeaWiFS. Two such events were studied. In one event material was transported in a thin strip between the northern wall of the Loop Current and an adjacent cyclone, connecting the eastern Campheche shelf (off the Yucatan Peninsula) and South Florida shelves. The other event began off the Louisiana shelf break as a small plume traced by chlorophyll and then developed into a long and thin feature which meandered to the shelf break off the northern Yucatan Peninsula, moving between a large anticyclone and several adjacent cyclones. These results indicate that inter-eddy advection plays a crucial role in developing the ocean color patterns observed in the satellite ocean color data. INDEX TERMS: 4255 Oceanography: General: Numerical modeling; 4275 Oceanography: General: Remote sensing and electromagnetic processes (0689); 4520 Oceanography: Physical: Eddies and mesoscale processes; 4855 Oceanography: Biological and Chemical: Plankton; 4528 Oceanography: Physical: Fronts and jets; KEYWORDS: Gulf of Mexico, Lagrangian, chlorophyll, SeaWiFS, connectivity, eddies

Citation: Toner, M., A. D. Kirwan Jr., A. C. Poje, L. H. Kantha, F. E. Muller-Karger, and C. K. R. T. Jones, Chlorophyll dispersal by eddy-eddy interactions in the Gulf of Mexico, J. Geophys. Res., 108(C4), 3105, doi:10.1029/2002JC001499, 2003.

\section{Introduction}

[2] Connection between different oceanic regions via advective transport is an important but poorly understood mechanism. Such "connectivity" has long been speculated to exist between various regions within and between the Caribbean Sea and the Gulf of Mexico due to similarities in organisms present in different ecosystems. It is of fundamental importance to understand the physical processes that control these pathways because of their impact on coral reef environments, marine biodiversity, and coastal fisheries [Ogden, 1997; Roberts, 1997].

[3] Many researchers have highlighted the importance of advection in controlling the spatial distribution of plankton. Early LANDSAT satellite images were interpreted by

\footnotetext{
${ }^{1}$ College of Marine Studies, University of Delaware, Newark, Delaware, USA. USA.

${ }^{2}$ College of Staten Island, City University of New York, New York,

${ }^{3}$ Colorado Center for Astrodynamics Research, University of Colorado, Boulder, Colorado, USA.

${ }^{4}$ Department of Marine Science, University of South Florida, St. Petersburg, Florida, USA.

${ }^{5}$ Department of Mathematics, University of North Carolina, Chapel Hill, North Carolina, USA

Copyright 2003 by the American Geophysical Union. 0148-0227/03/2002JC001499
}

Gower et al. [1980] in terms of mesoscale ocean features controlling phytoplankton patterns. That analysis and subsequent ones such as those of Denman and Abbott [1994] relied on spectral decomposition of satellite images to infer the underlying flow structures. In another study an idealized ocean model was used by Abraham [1998] to study how nondiffusive advection affected the spatial distribution of plankton by turbulent stirring. Wroblewski et al. [1975] and more recently Martin [2000] developed a relation between the minimum thickness of plankton patches, the effective diffusivity, and the strain rate of the velocity.

[4] More relevant to this study is the effect eddies have on biological transport in the Gulf of Mexico. Biggs and Muller-Karger [1994] showed that the interaction between cyclonic and anticyclonic eddies can transport high-chlorophyll continental shelf water seaward 100-200 km into the interior of the Gulf. Gilbes et al. [1996] documented the seasonal formation of chlorophyll plumes that extend along the West Florida Shelf. Muller-Karger et al. [1991] documented the entrainment of Mississippi River plume water along the edge of the Gulf of Mexico's Loop Current and its subsequent advection through the Florida Strait. MullerKarger et al. [1991] and Perez et al. [1999] also documented the entrainment of phytoplankton blooms off the northeastern border of the Campeche Bank into the "north wall" of the Loop Current and the advection of these plumes far into the Gulf of Mexico and into the Atlantic Ocean via the Florida Strait. 
[5] These studies benefited from the capability of synoptic mapping afforded by ocean color observations from space, in particular using the Coastal Zone Color Scanner (CZCS) sensor flown by NASA aboard the Nimbus-7 satellite between 1978 and 1986. Near-real time ocean color imagery obtained since 1997 over the eastern Gulf of Mexico with the Sea-viewing Wide-Field-of-View (SeaWiFS) sensor also shows frequent and complex transport of plankton biomass from the margins into the interior of the Gulf of Mexico.

[6] The goal of this study is to examine the relationship between the shape and extent of observed chlorophyll plumes and Lagrangian transport boundaries produced by coherent mesoscale structures in the Gulf, namely the Loop Current, rings, and eddies. To do this, SeaWiFS ocean color data are compared with a Lagrangian analysis of near surface currents obtained from a high resolution dataassimilating ocean model, the University of Colorado version of the Princeton Ocean Model (CUPOM) [Kantha et $a l ., 1999]$. Two separate plume events that occurred in the central/eastern Gulf of Mexico during 1998 (regions A and B shown in Figure 1) are analyzed. During these plume events, the SeaWiFS data clearly show large (order of 500 $\mathrm{km}$ long) chlorophyll plumes extending from the shelf into deep water. In mid-April, one event generated a plume that extended from the northeastern Campeche/Yucatan shelf across the Gulf to the southern West Florida Shelf. The other event, which occurred between mid-May and early June, produced a plume that extended from the Louisiana Shelf to the northern Yucatan Shelf break. Time scales for both plumes are on the order of 10 days, indicating intense episodic biological connectivity between different shelf environments can occur rapidly in the Gulf.

[7] The Lagrangian analysis of the CUPOM relies on the computation of material curves [Rom-Kedar et al., 1990; Ridderinkhof and Loder, 1994; Rogerson et al., 1999; Kuznetsov et al., 2002] to delineate advective pathways for particles and to provide a geometric template of the water parcel transport induced by identifiable coherent features in the Eulerian field. These material curves provide an objective means for investigating plume formation in the model velocity field. For the two plumes analyzed here, the coincidence of this geometric template with satellite-derived ocean color data is striking. Not only does this coincidence validate the model skill, but it also highlights the potential of modern numerical circulation models for ecosystem management purposes.

[8] Section 2 describes the model specifics, the ocean color data, and the regions of interest. A technical discussion and background of the Lagrangian analysis method is given in section 3. Section 4 describes the ocean color data and model flow in terms of the Lagrangian analysis and compares the plume patterns with numerically generated plumes. Discussion of the results are in section 5.

\section{Data}

[9] This study uses ocean currents obtained from a dataassimilating ocean model in conjunction with chlorophyll estimates obtained from a satellite mounted ocean color sensor. Together, these two independent data sets describe how chlorophyll plumes propagate from the continental

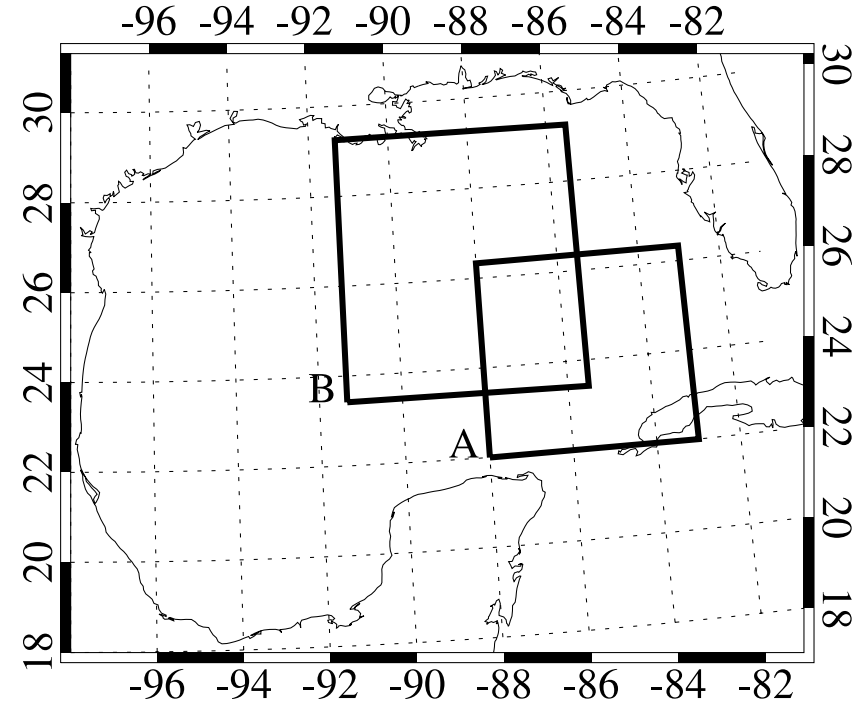

Figure 1. Regions in the Gulf of Mexico used for this study: Region A is $500 \times 509 \mathrm{~km}$ and Region B is $583 \times$ $648 \mathrm{~km}$.

margins into the open Gulf across distances of several hundred kilometers. Sections 2.1 and 2.2 describe the specifics of these two data sets, while the phenomena analyzed in section 4 is introduced in section 2.3.

\subsection{Model}

[10] The state of the art, primitive equation CUPOM [Kantha et al., 1999; Lopez and Kantha, 2000], which incorporates a data-assimilation module capable of assimilating both in situ data and remotely sensed data, is used to generate the near surface current fields for the analysis. A regional version of CUPOM configured for the Gulf, with 24 vertical sigma levels and a horizontal resolution 1/12 degree, has been tested in both hindcast and nowcast/ forecast modes extensively against proprietary data from the offshore oil industry and is often used in an operational manner by this industry [Kantha et al., 1999; Schaudt et al., 2001].

[11] Along-track TOPEX/Poseidon and ERS-2 altimeter data and the near-real-time sea surface temperature are assimilated using an optimal-interpolation-based data assimilation scheme, The model is forced by the NOGAPS winds. Inflow through the Yucatan Channel is prescribed from climatological data, while outflow through the Florida Straits evolves with model physics. Modification [Kantha and Clayson, 1994] of the original POM mixed layer parameterization [Mellor and Yamada, 1982] improves depiction of near-surface currents, sea surface temperature, and upper layer heat content.

[12] Two detailed comparisons of this model with in situ, near-surface $(50 \mathrm{~m})$ drifter data have been made recently. Toner et al. [2001] showed that the model is able to reproduce drifter paths adequately, and Kuznetsov et al. [2002] showed that a Lagrangian analysis based on generating specific material curves [Miller et al., 1997; Haller and Poje, 1998; Poje and Haller, 1999] was able to delineate the boundaries of coherent structures in the eastern Gulf. Moreover, Kuznetsov et al. [2002] used drifter data to 
document flow characteristics near the material curve boundaries computed from the model flow. These studies showed that the model "hindcasts" represent a reasonably accurate state of the Gulf.

\subsection{SeaWiFS}

[13] The SeaWiFS ocean color data, collected via a ground receiving station located at the University of South Florida, have a nominal spatial resolution of $1 \mathrm{~km}$ and are processed to chlorophyll-a using the standard and most current NASA algorithms and ancillary data using the SeaWiFS Data Analysis System (SeaDAS software package) distributed by NASA. To remove spatial gaps caused by missing data, a 10-day running mean is applied to the mapped daily data product. For purposes of this analysis the accuracy of chlorophyll-a concentration estimates is less important than the relative changes observed in the satellitederived chlorophyll-a fields in space and time. Of particular interest and utility is the application of chlorophyll-a as a tracer of biological advection and connectivity.

\subsection{Plumes}

[14] The regions considered in this study are labeled A and $B$ in Figure 1. SeaWiFS data are displayed in two colors, green and yellow, which respectively show the high $\left(>1.5 \mathrm{~g} / \mathrm{m}^{3}\right)$ and lower $\left(>0.25 \mathrm{~g} / \mathrm{m}^{3}\right)$ concentrations of chlorophyll in Figures 2 and 3. White represents chlorophyll data which is less than $0.25 \mathrm{~g} / \mathrm{m}^{3}$ and grey indicates missing data (due to either land mass or cloud cover masks). Figure 2 shows a plume that extends from the eastern Yucatan Shelf toward the southern West Florida Shelf in mid April, 1998 (Region A of Figure 1). Figure 3 shows a plume that forms on the Louisiana Shelf and extends almost to the northern Yucatan Shelf from mid May to the beginning of June, 1998 (Region B of Figure 1). Higher chlorophyll values occur in the northwestern part of Region B as a concentrated pattern that moves slowly off the Louisiana Shelf but does not become entrained into the plume. The results of the Lagrangian analysis (see section 4.2) of the model data (see section 2.1) indicate the advective mechanisms that prevent this entrainment.

[15] The black contours in Figures 2 and 3 are of the model sea surface height contoured at $0.1 \mathrm{~m}$ intervals, and the arrowed circular arcs indicate the sense of flow generated by the coherent features. Figure 2 shows the Loop Current in the southeast corner of the image, an adjacent cyclone in the center, and an anticyclone to the northwest. Figures $3 \mathrm{a}$ and $3 \mathrm{~b}$ show a large cyclone/anticyclone pair with the anticyclone to the west. On 16 May a small cyclone is present to the north of the anticyclone just south of the shelf break (indicated by the $110 \mathrm{~m}$ isobath), and on 21 May another small cyclone is to the east of the anticyclone. By 31 May, these two smaller cyclones merge into a single, larger cyclone to the north of the anticyclone and west of the plume. The larger cyclone in the southeast of the region splits, forming another cyclone on the east side of the plume.

\section{Methods}

[16] Geometric Lagrangian analysis of ocean currents determine the spatial patterns of a conservative tracer.

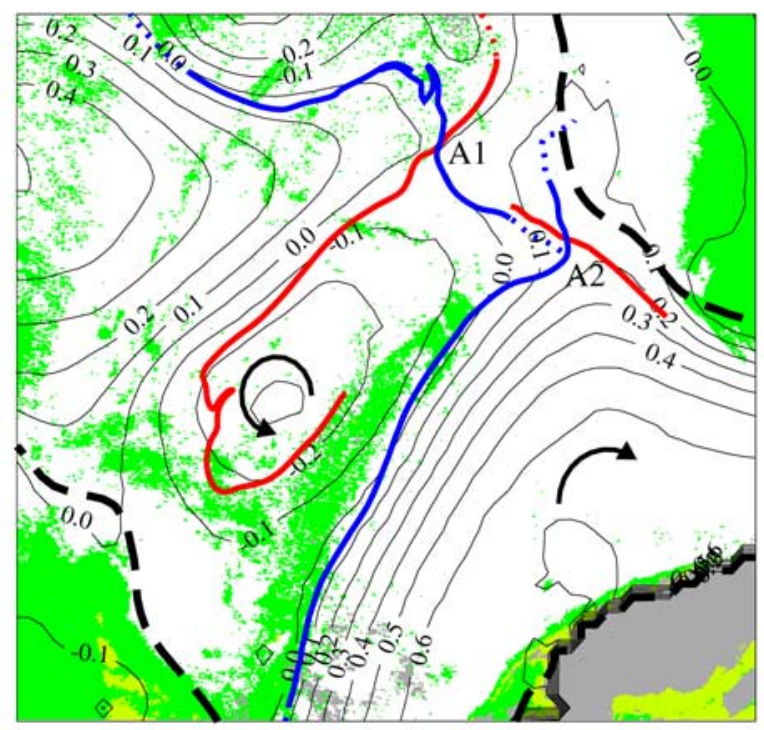

(a) April 12

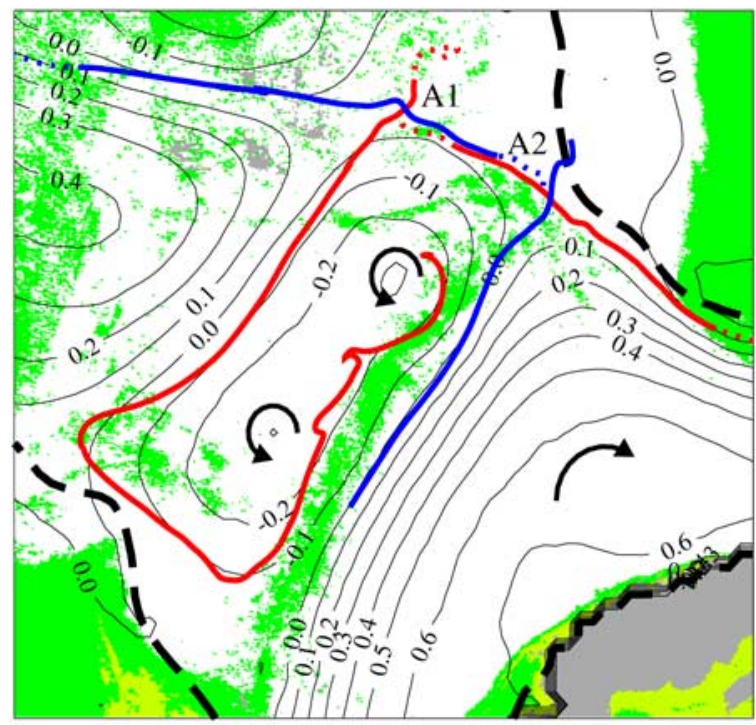

(b) April 17

Figure 2. Analysis of Region A during a plume event between the eastern Yucatan Shelf and the southwest Florida Shelf. Model height (measured from rest value) and material curves are superimposed on ocean color data. Chlorophyll values exceeding $0.25 \mathrm{~g} / \mathrm{m}^{3}$ are shown in green, values exceeding $1.5 \mathrm{~g} / \mathrm{m}^{3}$ are shown in yellow, values less than $0.25 \mathrm{~g} / \mathrm{m}^{3}$ are white, and missing data is grey. Red (blue) curves are outflowing (inflowing) manifolds. Dotted ends of manifold curves indicate that the manifold was truncated for clarity. Counter clockwise arrows indicate the sense of cyclonic rotation, and the clockwise arrow is the direction of Loop Current flow. The dashed black line indicates the $110 \mathrm{~m}$ isobath. 


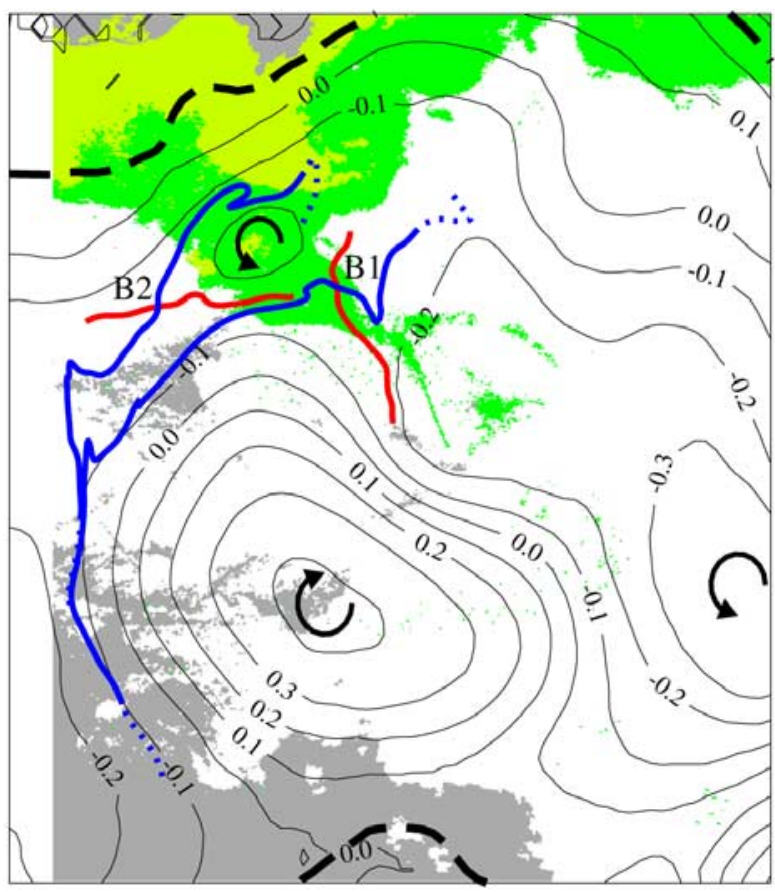

(a) May 16

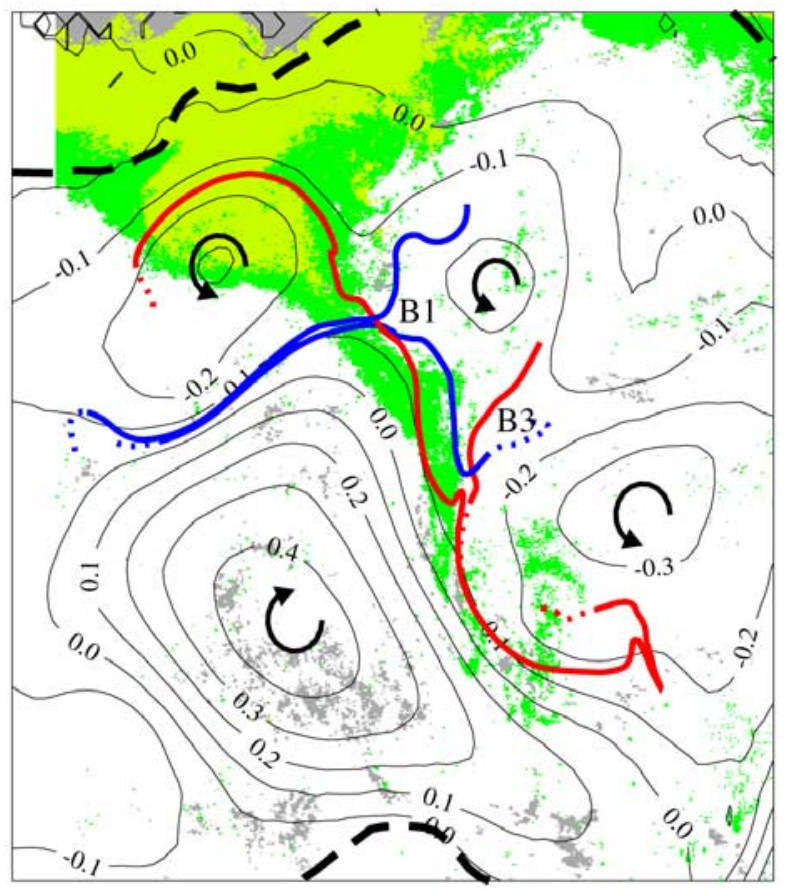

(c) May 31

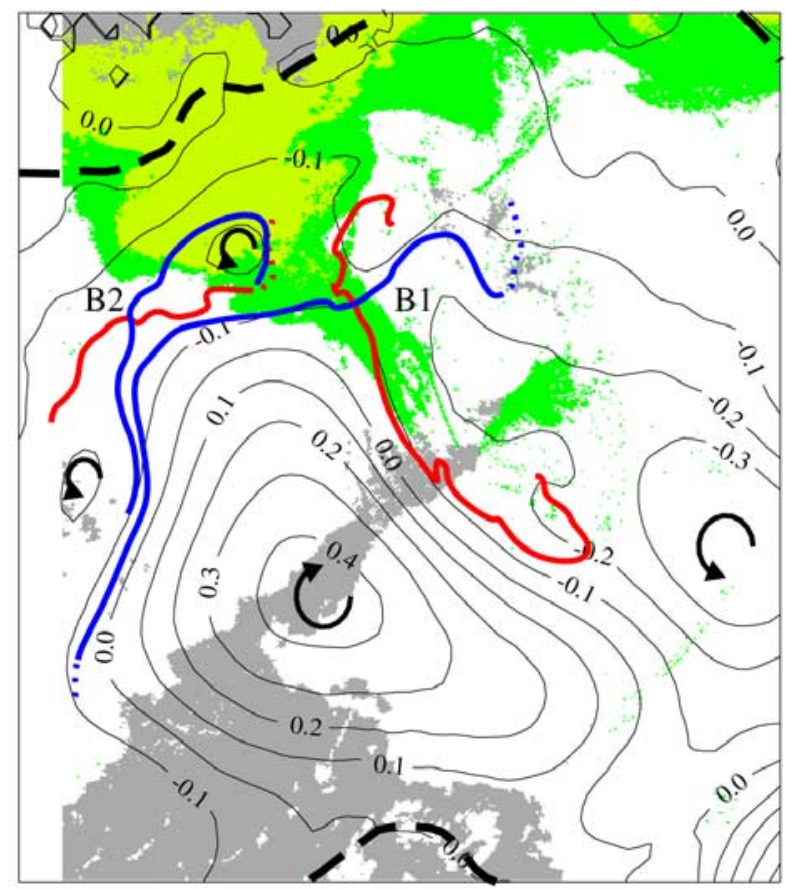

(b) May 21

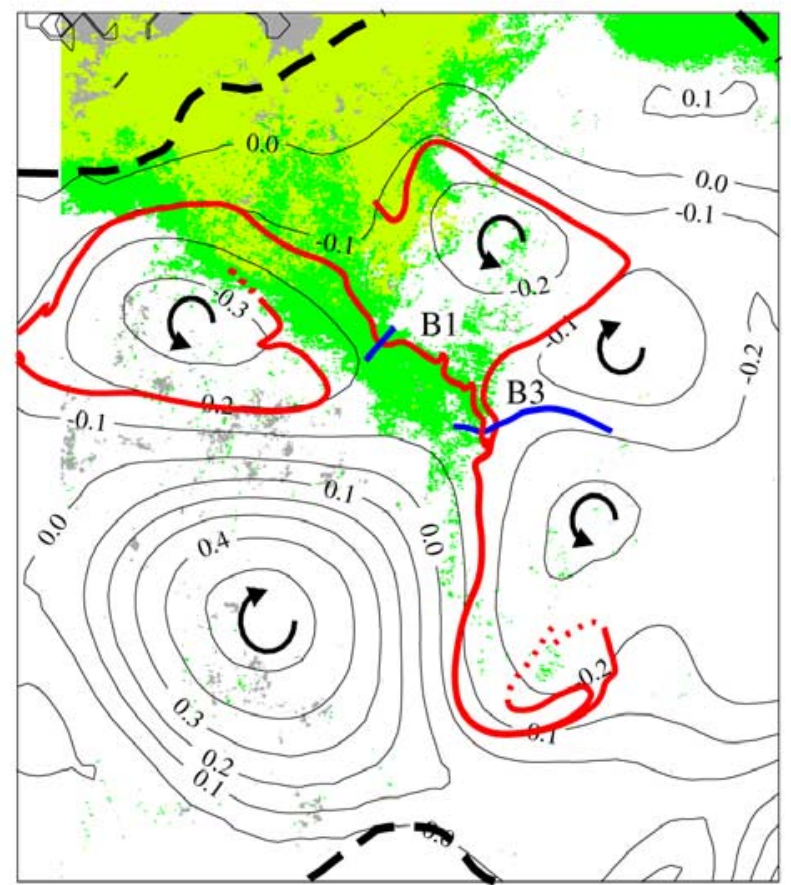

(d) June 8

Figure 3. Analysis of Region B during a plume event off of the Louisiana Shelf. Clockwise arrows indicate the sense of anticyclonic rotation. Other figure details are the same as in Figure 2. 
"Ocean color" is modified by aquatic constituents that may or may not behave conservatively. For example, if color depends on phytoplankton concentration, it will change along trajectories due to both physical processes, such as small scale mixing and vertical motion, and biogeochemical processes, such as changes in phytoplankton production, grazing, community structure, and factors like temperature or nutrient availability. Colored dissolved organic matter (CDOM) associated with the discharge of the Mississippi and smaller local rivers, which due to its yellow color looks much like phytoplankton from space, serves as a conservative tracer of salinity [Del Castillo et al., 2000, 2001; Hu et $a l ., 2003]$. The plumes observed extending from the Yucatan Peninsula (Region A) into the open Gulf are likely to be dominated by phytoplankton [Perez et al., 1999], and maintained by nutrients supplied through advected shelf water, upwelling which occurs at the Loop Current/cyclone boundary, or a combination of both. Presumably, a community of grazers (larvae or even larger animals) are also advected seaward with the phytoplankton, which might hasten the decrease of phytoplankton concentration within these plumes. The color of plumes extending off the Mississippi delta and adjacent coastal zones could be more persistent and less dependent on such biological processes. The actual processes that sustain elevated apparent chlorophyll concentrations within the various plumes are not entirely clear without in situ data. The remotely sensed satellite data, however, do provide large-scale patterns which may be interpreted in terms of advection processes. Indeed, this argument is bolstered by the work of Gower et al. [1980] and Denman and Abbott [1994], who show the wavenumber spectra of remotely sensed chlorophyll patterns is consistent with the spectrum of passive scalars advected by mesoscale turbulent motions.

[17] Geometric techniques have been successfully used to understand and quantify the dynamics and transport of nondiffusive particles in a variety of contexts. Starting with the work of Aref [1984], MacKay et al. [1984], and RomKedar et al. [1990] in analytic, time-periodic velocity fields, the ideas of chaotic advection or Lagrangian chaos have been extended to increasingly realistic geophysical flows by Ridderinkhof and Loder [1994], Loder et al. [1997], Rogerson et al. [1999], Poje and Haller [1999], Coulliette and Wiggins [2000], Berloff et al. [2002], Koh and Plumb [2000], and Miller et al. [2002]. More relevant to this study is Kuznetsov et al. [2002] who identified the material curves governing the transport properties associated with the pinch off of a Loop Current Ring and the cleavage of an anticyclone by a cyclone using velocity fields produced by the present CUPOM.

[18] The critical flow features for this type of analysis are hyperbolic trajectories that attract nearby particles along one direction and repel them in another, thereby producing exceptionally strong fluid deformation. A patch of fluid centered at the hyperbolic trajectory will undergo distortion with maximum compression along one axis and maximum stretch along another. These directions lie along one dimensional material curves that flow from the hyperbolic trajectory (stretch direction) or towards the trajectory (compression direction). These material curves are called the inflowing and outflowing manifolds associated with the hyperbolic trajectory respectively. In contrast, upwelling or downwelling regions cause either isotropic expansion or contraction of blobs near the critical point [Carstoiu, 1954; Kirwan, 1975].

[19] A variety of algorithms may be used to identify hyperbolic trajectories and Lagrangian structures in fluid flow. Techniques based on finite time Lyapunov exponents [Pierrehumbert, 1991], finite size Lyapunov exponents [Boffetta et al., 2001], Lagrangian analogs of the OkuboWeiss criteria [Haller, 2000; Lapeyre at al., 2001], and analysis of the strain acceleration tensor [Haller, 2001] have been proposed. A relatively simple diagnostic tool proposed by K. Bowman (personal communication, 1999) is to locate regions of high relative (two-particle) dispersion in the Lagrangian field [Jones and Winkler, 2000].

[20] The location of hyperbolic trajectories may not be determined with direct numerical integration of a single trajectory. This is due to a combination of numerical roundoff (present in all advection routines) and imprecise knowledge of the initial location of the hyperbolic trajectory. In hyperbolic regions, almost all numerical trajectories exit the region along the stretch direction. However, a "straddling" technique may be employed to take advantage of the combination of stretch and compression to locate the hyperbolic trajectory via the material curves that emanate from it. Since the dynamical significance of the hyperbolic trajectory is of finite duration, a time interval of interest must be determined prior to computing the material curves that align with the manifolds. Material line segments are initialized along the outflowing (inflowing) direction and then advected with the forward (backward) flow to form the outflowing (inflowing) manifolds. As documented by Miller et al. [1997], Haller and Poje [1998] and Kirwan et al. [2003], the technique is robust in the context of geophysically relevant velocity fields. An identical method was employed by Kuznetsov et al. [2002] in analyzing data from the CUPOM.

[21] This study uses essentially the same methods as Kuznetsov et al. [2002], except that relative dispersion and Lagrangian trajectory maps are employed to identify the appropriate "straddling" locations. Tests indicate the same lack of sensitivity to initialization specifics as reported by Kuznetsov et al. [2002]. Numerical integration is performed with the LSODA routine from the public domain library ODEPACK using bicubic spatial and linear temporal interpolation of the gridded model velocity fields.

[22] An example of how fluid behaves near the hyperbolic trajectory (identified by the intersecting red and blue curves) labeled A2 in Figure 2 is shown in Figures $4 a, 4 b$, $4 \mathrm{c}$, and $4 \mathrm{~d}$. The patch of fluid (green) shown in Figure $4 \mathrm{a}$ flows towards the hyperbolic trajectory (see Figure 2) along the inflowing manifold (blue). Four days later, this patch flows away from the hyperbolic point along the outflowing manifold (red). The elongated geometry of the patch, which is aligned with the inflowing manifold on 14 and 15 April and then aligned with the outflowing manifold on 17 and 18 April, becomes a disc of radius $26 \mathrm{~km}$ on 16 April (not shown) centered at the hyperbolic trajectory.

[23] Material curves used in section 4 (and the previous example) are computed from the model horizontal velocity at $50 \mathrm{~m}$. The SeaWiFS instrument measures water leaving radiance generated within approximately one optical depth of the surface of the ocean. In the core of the Loop Current, 


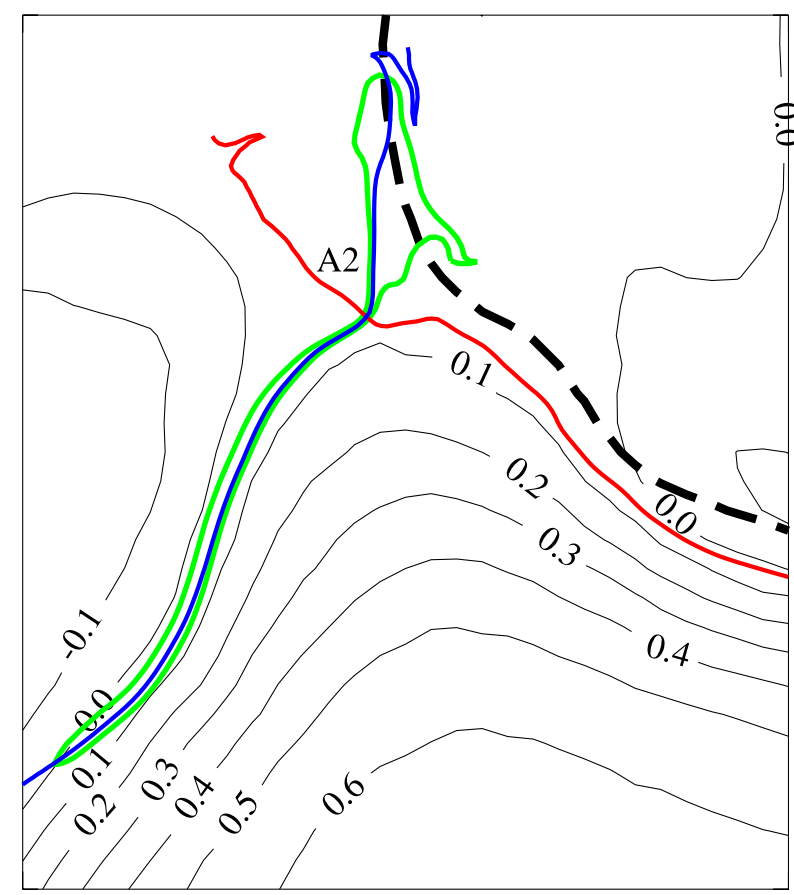

(a) April 14

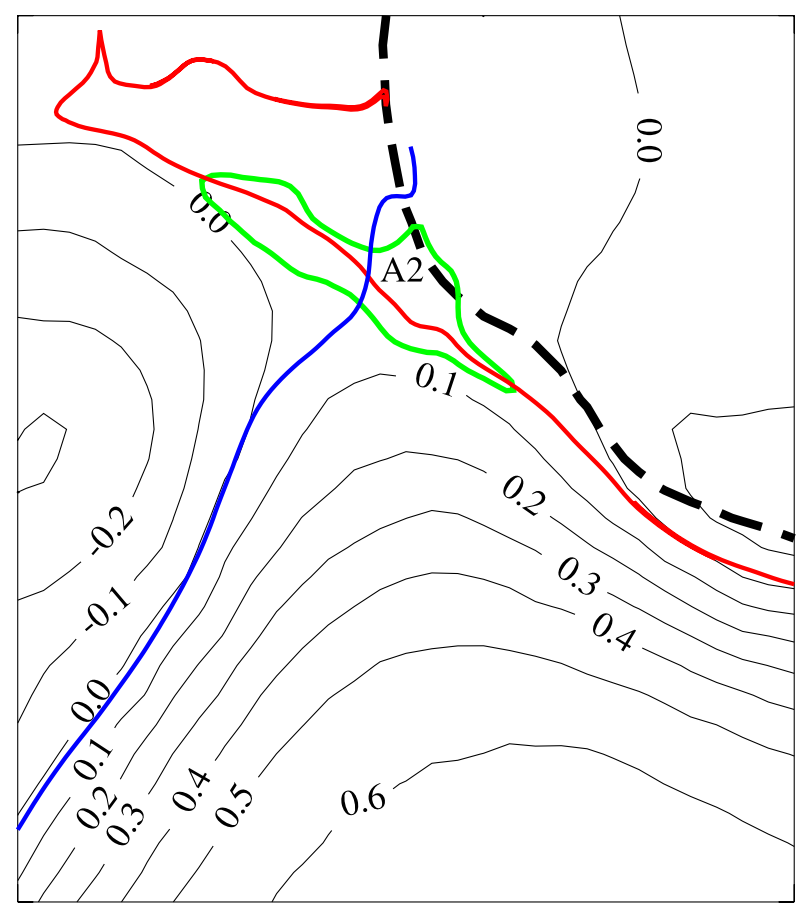

(c) April 17

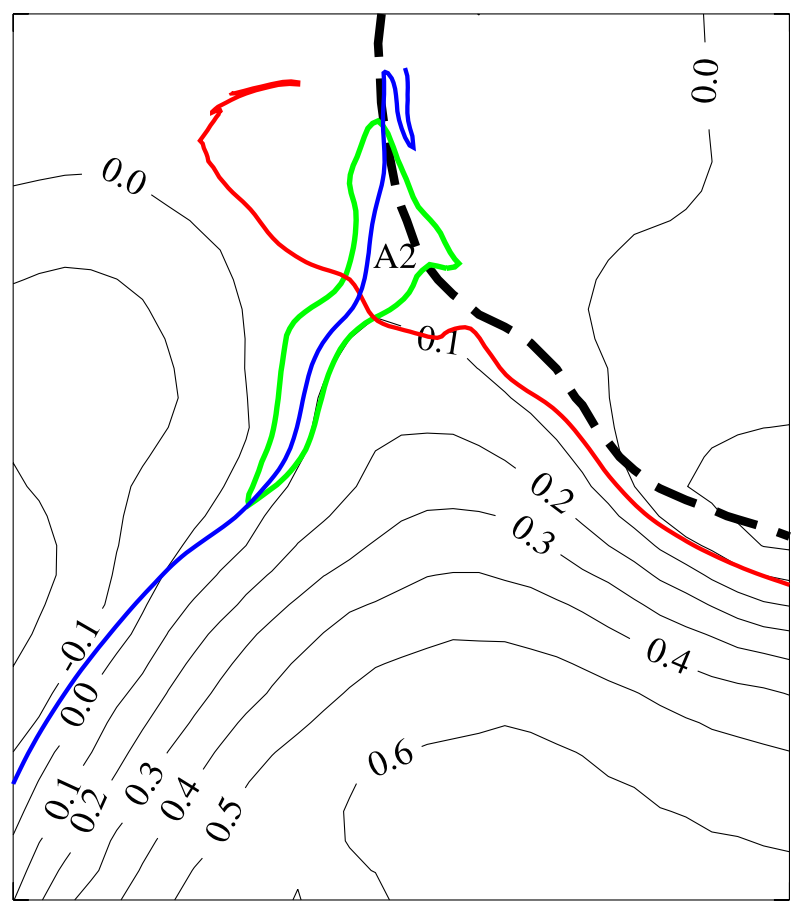

(b) April 15

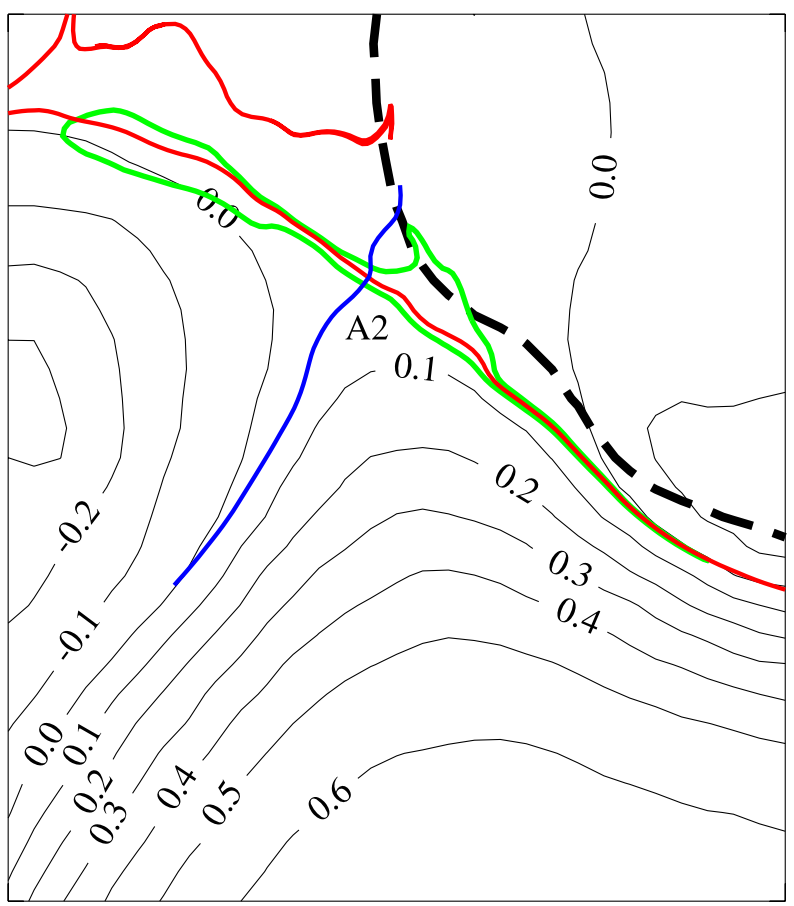

(d) April 18

Figure 4. The behavior of water near the hyperbolic point A2 labeled in Figure 2. Dimensions of this region are $250 \times 278 \mathrm{~km}$. 
which can feature some of the clearest waters of the Atlantic Ocean during summer months, the color observed by SeaWiFS is effected by approximately the upper $100 \mathrm{~m}$. However, as chlorophyll or CDOM concentration increases, this depth becomes shallower. In areas where apparent chlorophyll-a is greater than $0.25 \mathrm{~g} / \mathrm{m}^{3}$, the depth of the estimate is likely of the order of $15-20 \mathrm{~m}$ and shallower at even higher concentrations. In the numerical model used here, horizontal velocity fields at $10 \mathrm{~m}$ and $50 \mathrm{~m}$ depths produce coherent feature boundaries which are qualitatively the same and quantitatively similar [Kuznetsov et al., 2002]. The $50 \mathrm{~m}$ depth is chosen to represent the near-surface flow because wind effects there are minimal and do not mask the signature of the underlying mesoscale coherent features of interest.

\section{Results}

[24] Superposition of both the Lagrangian analysis of the model velocity and the model sea surface height on the ocean color data indicates how the observed shape and extent of the plume can be described and interpreted using the modeled currents. The derived material curves determine the Lagrangian boundaries of the Loop Current, cyclones, and anticyclones thus identifying the role these coherent structures play in plume formation and maintenance. The Lagrangian analysis concentrates on two hyperbolic trajectories in Region A (labeled A1 and A2 in Figure 2) and three such trajectories in Region B (labeled B1 through B3 in Figure 3). Throughout, the inflowing and outflowing manifolds emanating from a hyperbolic trajectory, A1 for example, are referred to as A1-in (blue curves) and Al-out (red curves), respectively.

[25] During their integration, and especially for longer times (10 to 20 days), the computed material curves foliate as they stretch and encounter other hyperbolic trajectories associated with different cyclones and anticyclones in the Gulf. Since the interaction with remote coherent features is not the goal of the present analysis, the manifolds are truncated when they become entangled and only those portions that identify the advective paths corresponding to the plumes of interest are shown.

[26] The five selected hyperbolic trajectories have sustained stretching rates of approximately 1 day $^{-1}$. Stretching peaks can be as strong at 2 day $^{-1}$, while the hyperbolic trajectories tend to wane when stretching reduces to less than 0.5 day $^{-1}$. With this sustained stretching the computed manifold segments shown in Figures 2 and 3 are robust; the same curves are obtained for many different orientations and initialization times of the material line segments. Hyperbolic trajectories in general move slowly, but when cyclones or anticyclones adjust their relative positions, the manifold patterns develop "kinks" that are independent of the initialization specifics. The "kinks" do not affect our results.

\subsection{Region A}

[27] Figure 2 concentrates on the observed evolution of a chlorophyll plume in the Yucatan Region due to the interaction of the Loop Current with an adjacent cyclone. On 12 April the plume extends well over half of the distance between the two shelves. Five days later, the plume tip approaches the shelf break off southwestern Florida. The
Lagrangian boundaries of the Loop Current and the adjacent cyclone are computed from material curves that emanate from two hyperbolic trajectories located off southwestern Florida, labeled A1 and A2 in Figure 2. The material curves associated with A1 are initialized on 6 April (A1-out) and 26 April (A1-in), while those associated with A2 were initialized on 11 April (A2-out) and 19 April (A2-in).

[28] The Lagrangian analysis on 12 April clearly shows the location of an advective mixing channel between the southern branch of A2-in, which marks the strong advective barrier of the Loop Current edge, and the southern branch of A1-out, which wraps around the cyclone thereby delineating it. The geometry indicates that the cyclonic ring grows by entraining water from the region between these two curves, conveniently marked by the chlorophyll plume.

[29] By 17 April both the computed mixing channel and the observed chlorophyll plume narrow appreciably. The southwestern edge of the cyclone (A1-out) approaches both the Yucatan Shelf break and the southeastern edge approaches the Loop Current boundary (A2-in). The chlorophyll plume is contained almost entirely in the computed mixing channel marking the pathway of water parcels entrained into the cyclone. The classic "mushroom" pattern observed at the tip of the chlorophyll plume coincides with the location of hyperbolic trajectory A2 and the associated transport barrier, A2-out. The mushrooming occurs before the plume encounters the Florida Shelf Break and appears to be a consequence of the cyclone/Loop Current interaction.

[30] On both days, there exists a remarkably strong correlation between the shape and extent of high chlorophyll water and the coherent structure boundaries delineated by the Lagrangian analysis. Whether the presence of chlorophyll rich water along the edge of the strong cyclone is due entirely to the advective stripping of shelf water as indicated by the manifold geometry or to upwelling processes on the edge of the cyclone is an issue that is beyond the scope of this study. However, the present results do indicate that Lagrangian coherent structure boundaries and advective pathways play a key role in the formation and maintenance of observed chlorophyll plumes.

\subsection{Region $B$}

[31] Figure 3 shows the formation and evolution of a chlorophyll plume (likely dominated by high levels of CDOM) extending approximately $500 \mathrm{~km}$ from the Louisiana Shelf toward the northern Yucatan Shelf starting from a small intrusion in mid-May to a fully extended feature by early June. Advective processes during this time are governed by the interaction of three cyclones and one anticyclone. Throughout this period the large anticyclone remains in the open Gulf to the southwest of the plume just north of the Yucatan Shelf break. The two cyclones near the Louisiana Shelf break on either side of the plume are instrumental in the plume formation. Three hyperbolic trajectories, marked by B1, B2, and B3, are used for the Lagrangian analysis. Manifolds for B1 were initialized on 11 May (B1-out) and 8 June (B1-in), for B2 on 12 May (B2-out) and 26 May (B2-in), and for B3 on 22 May (B3-out) and 11 June (B3-in).

[32] On 16 May (Figure 3a) a small cyclone south of the high chlorophyll patch (yellow), northeast of B2, and northwest of B1, is bounded by the eastern branch of B2-out and 
the northern branch of B2-in. By 21 May another cyclone south of B2 appears, bounded by the southern branches of B2-out and B2-in, and the two merge into a larger cyclone, seen on 31 May. The hyperbolic trajectory B2 disappears in this merger, and the resulting larger cyclone is marked by the northern branch of B1-out and the western branch of B1-in. The large cyclone to the southeast of B1 on 21 May, roughly bounded by the eastern branch of B1-in and the southern branch of B1-out, splits into two smaller cyclones by 31 May which introduces the hyperbolic trajectory B3. One of these cyclones is to the north of B3, bounded by the northern branches of B3-out and B3-in and the eastern branch of B1-in. The other is to the south of B3 and bounded by the merging southern branches of B1-out and B3-out and the eastern branch of B3-in. By 8 June, a small anticyclone appears between these two cyclones to the northeast of B3, between the northern branch of B3-out and the eastern branch of B3-in, but does not appear to play a direct role in the plume event.

[33] In the early plume formation, between 16 May and 21 May, the amount of high apparent chlorophyll or CDOM water (yellow patches in Figures $3 a$ and $3 b$ ) off the shelf seaward of the shelf break increases significantly. While the cause of this increase is unclear, either from upwelling on the cyclone boundary or other biological processes in the formation region, the Lagrangian dynamics associated with northern branches of B2-in and B1-out in conjunction with the eastern branch of B2-out explain both its slight westward propagation and lack of seaward advection. On 21 May, the northern branch of B1-out coincides with the eastern edge of the lower apparent chlorophyll (green) patch and, together with the eastern branch of B2-out, forms a barrier to the seaward advection of the core chlorophyll rich region northeast of the small cyclone. The geometry of the northern branch of B2-in between 16 May and 21 May indicates the core chlorophyll rich region is becoming entrained into the cyclone, thereby moving slightly westward.

[34] Evolution of the chlorophyll plume can be explained in terms of the Lagrangian dynamics in the vicinity of hyperbolic trajectories as determined by these material boundaries. Consistent with Lagrangian dynamics in the vicinity of the hyperbolic trajectory $\mathrm{B} 1$, the southern branch of B1-out coincides with the formation of the extended plume throughout its development. The location of the eastern and western branches of B1-in indicates how open Gulf water with low apparent chlorophyll concentration is advected into the region from the side thus compressing the plume in this direction. This is most clearly seen on 31 May.

[35] The feature dissipates south of B3 and widens north of B1 between 31 May and 8 June. Stretching rates near both $\mathrm{B} 1$ and $\mathrm{B} 3$, which are estimated from the eigenvalues $\lambda_{B 1, B 3}$ of the velocity gradient matrix evaluated at the respective hyperbolic trajectories, weaken during this time. Near B1, stretching decreases from $\lambda_{B 1}=1.3$ day $^{-1}$ on 21 May to $\lambda_{B 1}=1.0 \mathrm{day}^{-1}$ on 31 May to $\lambda_{B 1}=0.83 \mathrm{day}^{-1}$ on 8 June. Near B3, stretching decreases from $\lambda_{B 3}=0.91$ day $^{-1}$ on 31 May to $\lambda_{B 3}=0.63$ day $^{-1}$ on 8 June. Weakening of hyperbolic trajectories is indicative of their finite-time nature and typically occurs just before their disappearance. Both of these hyperbolic trajectories disappear a few days after 8 June. The widening of the filament as the stretching rate decreases is consistent with the results of Martin [2000].

[36] On 8 June the shortened plume terminates along the advective barrier associated with both branches of B3-out. The northern branch of B3-out wraps around the cyclone to the east of the plume and aligns with the eastern edge of the high chlorophyll region. Similarly, the northern branch of B1-out wraps around the cyclone to the west of the plume, returns towards B1, and then aligns with the western edge of the lower chlorophyll region. Together, these two outflowing material curves indicate how the "wedge" shape of the feature off the shelf break is maintained.

\subsection{Numerical Plumes}

[37] The manifolds in sections 1 and 2 do not directly provide information regarding the time scales and distances of advection in the CUPOM. Although the manifold patterns are consistent with the plumes' evolution, a more rigorous test that directly compares the evolution of fluid particles "tagged" with elevated chlorophyll is appropriate. Even though the manifolds detail the boundaries between the eddies, rings, and Loop Current, the magnitude of advection should be consistent with the plume evolution in order to bolster the hypothesis that advection is a controlling mechanism.

[38] Particles forming the numerical plume are initialized at every chlorophyll datum exceeding the $0.25 \mathrm{~g} / \mathrm{m}^{3}$ threshold in regions where the water depth is greater than $110 \mathrm{~m}$ and then advected with the model $50 \mathrm{~m}$ horizontal velocity. For region A, the numerical plume evolves from 12 April to 17 April (compare Figures 5a and 5b with Figures 2a and $2 \mathrm{~b}$ ) and for region B it evolves from 16 May to 21 May (compare Figures 5c and 5d with Figures $3 \mathrm{a}$ and $3 \mathrm{~b}$ ).

[39] Figure 5b shows the tagged fluid between the cyclone and the Loop Current entrains into the cyclone via the channel delineated by the manifolds A2-in and A1out. The numerical plume corresponds well with the chlorophyll patterns on 17 April (compare Figure 2b with Figure $5 \mathrm{~b})$. Note that the tagged fluid to the east of A2-in compresses along the eastern branch of A2-out. Since the numerical plume does not tag water in depths less than the $110 \mathrm{~m}$ isobath, the flow off of the shelf into the southern portion of the plume is not captured.

[40] Figure 5d also shows that a narrow numerical plume forms along the southern branch of B1-out. The model currents indicate a strong westward flow along the shelf break. In particular the northeastern branch of B2-in details how the high chlorophyll patch just off the shelf break (see Figure 3a) propagates westward (see Figure 3b). These experiments indicate the expansion of the initial high chlorophyll patch between 16 May and 21 May (compare Figures $3 \mathrm{a}$ and $3 \mathrm{~b}$ ) is not primarily due to horizontal advection at $50 \mathrm{~m}$ since shelf water does not protrude significantly into the plume region. The experiment conducted with the surface velocity (not shown) generates essentially the same pattern with a slightly larger protrusion of shelf water. Tidal effects in the model might provide more information on the role advection plays in the initial chlorophyll patch expansion.

[41] The numerical plumes for both regions are more narrow than the chlorophyll patterns in the SeaWiFS data. The most obvious reason for this disparity is the lack of 


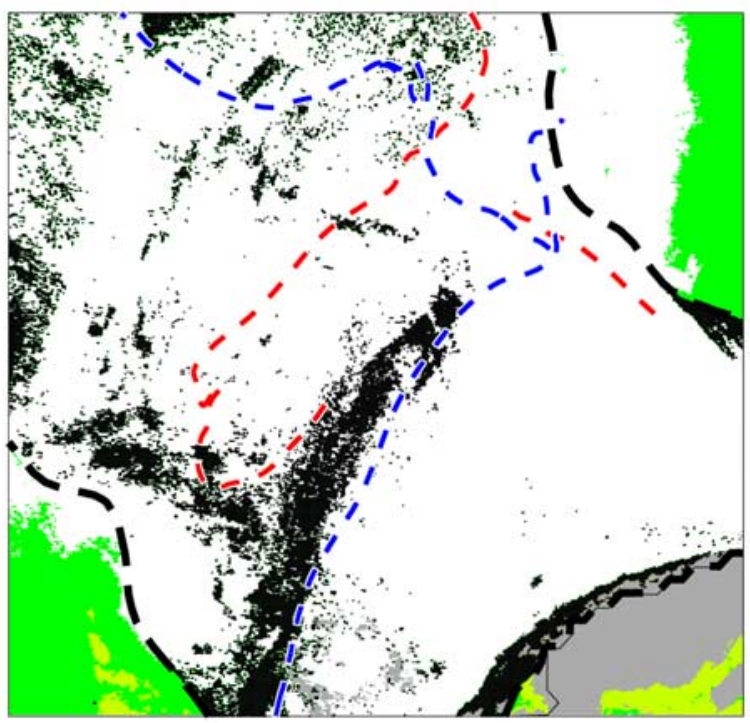

(a) Region A: April 12

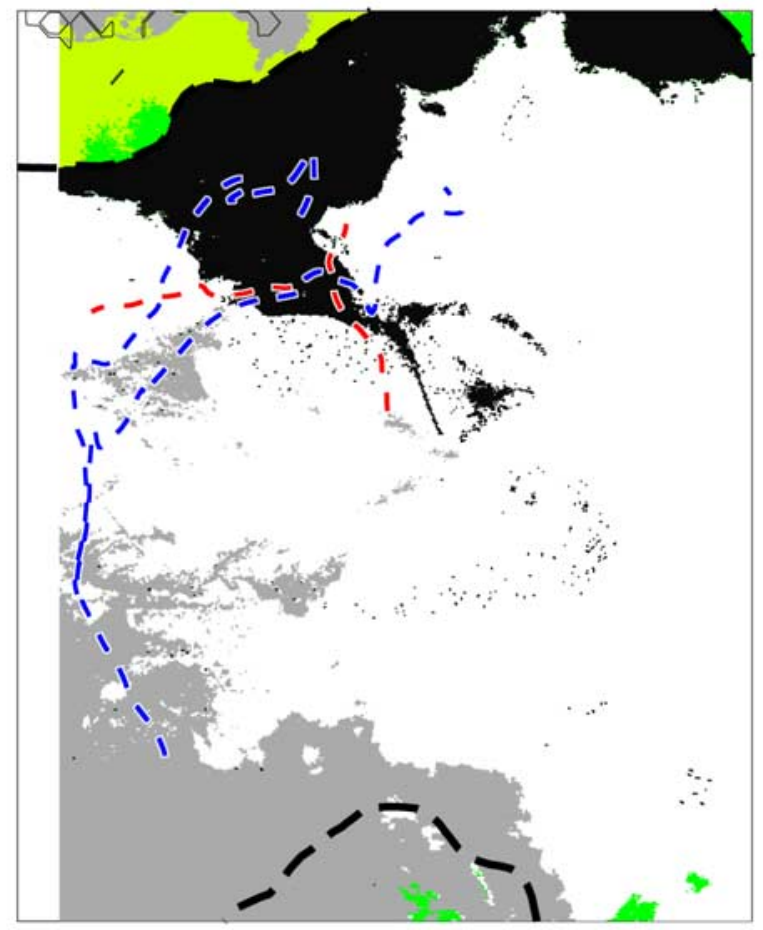

(c) Region B: May 16

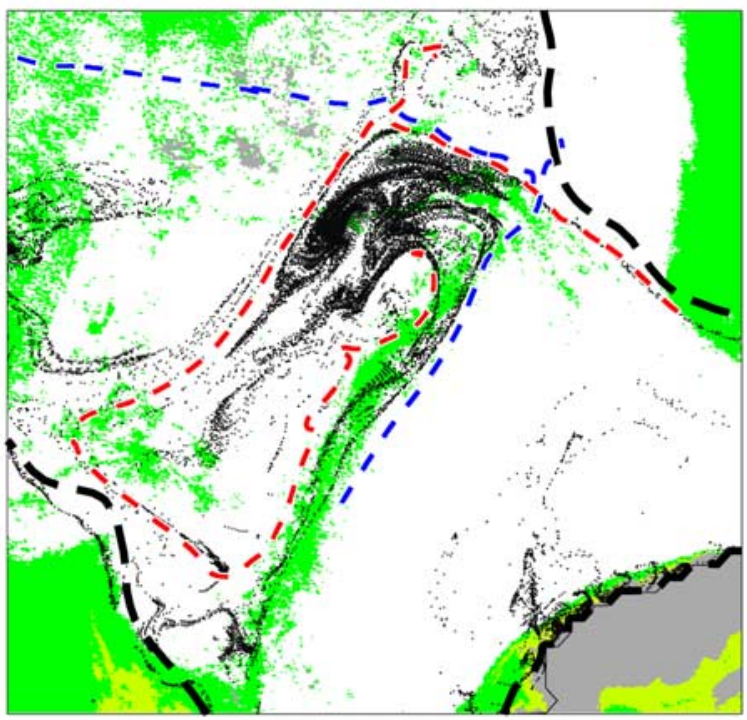

(b) Region A: April 17

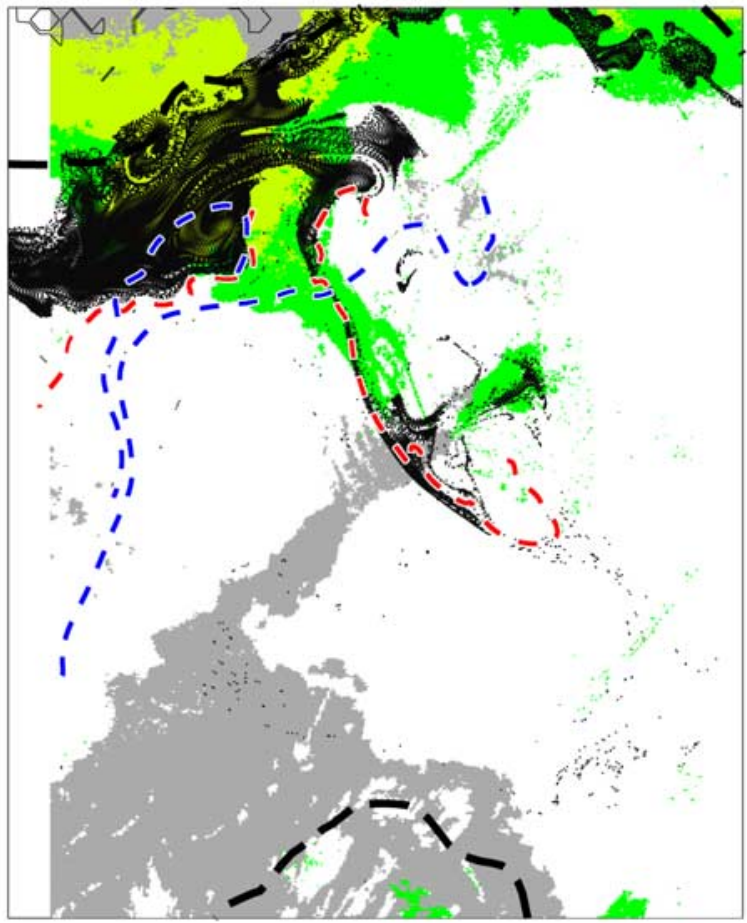

(d) Region B: May 21

Figure 5. Numerical plume evolution. Black dots indicate "tagged" water particles evolved with the model flow. 
diffusive effects in the advection algorithm. However, the overall agreement between the numerical and "real" plumes indicate that advection is a controlling factor.

\section{Discussion}

[42] This study compares chlorophyll plumes documented by SeaWiFS ocean color data to intereddy advective pathways obtained from near-surface currents of a data assimilating CUPOM. A Lagrangian method describes the evolution of two chlorophyll plumes in the Gulf of Mexico by delineating the relevant material boundaries of nearby coherent features. One plume evolves between a cyclone and the Loop Current, while the other evolves between an anticyclone and three cyclones. Despite the delay from the 10-day running mean applied to the SeaWiFS data and the fact that chlorophyll is not conserved along particle trajectories, the observed plumes follow the intereddy advective pathways of the model remarkably well. This result provides further evidence of the overall model accuracy and also highlights the usefulness of the Lagrangian method.

[43] Of particular interest from a biological perspective is the evidence of organic material (particulate and dissolved) and organism export from continental margins into the Gulf interior, and the connectivity that such transports represent between remote ecosystems. Ocean color data, provided previously by the CZCS and currently by SeaWiFS, show many areas around the globe where such biological export occurs. The present study demonstrates the utility of remote sensing data in establishing and monitoring such patterns of connectivity which previously have been inferred from climatological or long-term oceanic circulation patterns [Roberts, 1997]. The high spatial and temporal resolution afforded by remote sensing data, in concert with a Lagrangian analysis of an accurate, data-assimilating numerical model, details the specific connectivity events discussed here.

[44] Longhurst [1993] attributes the physical expression of chlorophyll plumes seen in satellite imagery of tropical oceans to eddy upwelling which can occur around the retroflection and associated anticyclonic features [Woods, 1988]. Longhurst particularly rejects the notion that the color in these plumes represents material advected from continental margins. In the Gulf of Mexico, however, the pathways produced by the Lagrangian analysis of the model currents show that advection of material from continental margins into the Gulf's interior does occur, and that it occurs on time scales commensurate with the appearance of chlorophyll plumes. As shown by the material curve geometry, horizontal off-shelf transport is typically confined to thin, intereddy mixing channels governed by the interaction of identifiable Eulerian coherent structures. Such channels are capable of rapidly stripping water from shelf regions and transporting it hundreds of kilometers into and across the Gulf. While the strictly horizontal analysis conducted here does not rule out eddy upwelling as a source of chlorophyll in the deep Gulf, it does indicate an alternate or commensurate explanation for the shape and size of satellite observed plumes.

[45] Velocity auto-correlation times computed from the model in the open Gulf show a disparity between Lagrangian time scales (on the order of days) and Eulerian time scales (on the order of months). This indicates quasiadiabatic dynamics for the particle motion surrounding the eddies and rings whereby particles move along streamlines for times shorter than the evolution time of the Eulerian field, thus confining exchange into and out of Eulerian structures to long, thin filaments of fluid. See, for example, Lebovitz and Neishtadt [1994]. This filamentary characteristic is seen in both the computed material curves and the elongated chlorophyll plumes.

[46] Physical mechanisms governing plume formation have been analyzed by Martin [2000] who shows that a plankton patch deformed by diffusion, strain, and biological growth has a minimum width given by $D_{\min }=\sqrt{\kappa / \lambda}$ where $\kappa$ is the effective diffusivity and $\lambda$ is the strain rate. The Yucatan/Florida and Louisiana/Yucatan plumes are about 25 $\mathrm{km}$ and $50 \mathrm{~km}$ wide, respectively, which is consistent with the higher stretching along the Loop Current. Although these widths depend on which chlorophyll-a threshold value is used to determine the plume edge, the Loop Current plume remains more narrow than the one off Louisiana regardless of their specific values.

[47] Prior studies of circulation and transport in the Gulf have focused extensively on the kinematics and dynamics of Loop Current rings. See, for example, Kirwan et al. [1984a, 1984b], Vukovich and Crissman [1986], Lewis and Kirwan [1987], Kirwan et al. [1988], Indest et al. [1989], Lewis et al. [1989], Forristall et al. [1992], Glenn and Ebbesmeyer [1993], and Hamilton et al. [1999] for kinematic analyses of Lagrangian data and Leben and Born [1993] for analysis of altimeter data. In contrast, except for a few studies such as Merrell and Morrison [1981], Merrell and Vazquez [1983], Hamilton [1992], and Vidal et al. [1994], less attention has been paid to the role of cold-core, cyclonic eddies. The dataassimilating CUPOM used for this study indicates that these cyclones are ubiquitous in the Gulf and have a dramatic effect on the advection of chlorophyll-rich waters from the shelf regions, across the open Gulf, and towards other shelf regions. Furthermore, there is no reason to presume that these surreptitious, intereddy pathways exist only when chlorophyll-rich waters are conveniently located to document them. Their role in the re-distribution of physical quantities such as heat, momentum, and salt might be substantial.

[48] Further studies should quantify the transport associated with the plume events and provide a three dimensional analysis of the advective paths. Moreover, to better understand the role nutrient depletion, grazing, and diffusion play in bioconnectivity a coupled biological submodel should be incorporated. See, for example, Fasham and Evans [2000] and Kantha [2003]. Tides are potentially important for initial plume formation and their inclusion in the model would greatly increase our understanding of how the cyclone/anticyclone interaction combines with tidal motion to initiate and generate cross-shelf advection. See Ohlmann et al. [2001] and the references therein for a discussion of cross-shelf advection in the Gulf.

[49] Acknowledgments. This research was supported by Office of Naval Research grants N00014-00-1-0019 (MT and ADK), N00014-J-1481 (CKRTJ), and N00014-02-1-1043 (LHK), NASA grant NAG5-11254 (FMK), and National Science Foundation grant ATM-02221 (MT and ACP). A. D. Kirwan Jr. acknowledges the Mary A. S. Lighthipe endow- 
ment to the University of Delaware. This is the USF Institute for Marine Remote Sensing contribution number 49. The authors acknowledge Orbimage and NASA for the SeaWiFS data.

\section{References}

Abraham, E. R., The generation of plankton patchiness by turbulent stirring, Nature, 391, 577-580, 1998.

Aref, H., Stirring by chaotic advection, J. Fluid Mech., 192, 115-173, 1984

Berloff, P. S., J. C. McWilliams, and A. Bracco, Material transport in oceanic gyres. Part I: Phenomenology, J. Phys. Ocean., 32, 764-796, 2002.

Biggs, D. C., and F. E. Muller-Karger, Ship and satellite observations of chlorophyll stocks in warm- and cold- core rings in the western Gulf of Mexico, J. Geophys. Res., 99, 7371-7384, 1994.

Boffetta, G., G. Lacorata, G. Radaelli, and A. Vulpiani, Detecting barriers to transport: A review of different techniques, Physica D, 159, 58-70, 2001

Carstoiu, I., Vorticity and deformation in fluid mechanics, J. Rational Mech., 3, 691-717, 1954.

Coulliette, C., and S. Wiggins, Intergyre transport in a wind-driven, quasigeostrophic double gyre: An application of lobe dynamics, Nonlinear Proc. Geophys., 7, 59-85, 2000.

Del Castillo, C., F. Gilbes, P. Coble, and F. E. Muller-Karger, On the dispersal of riverine colored dissolved organic matter over the West Florida Shelf, Limnol. Oceanogr, 45, 1425-1432, 2000.

Del Castillo, C., P. Coble, R. Conmy, F. E. Muller-Karger, L. Vanderbloemen, and G. Vargo, Multispectral in-situ measurements of organic matter and chlorophyll fluorescence in seawater: Documenting the intrusion of the Mississippi River Plume in the West Florida Shelf, Limnol. Oceanogr., 46, 1836-1843, 2001

Denman, K. L., and M. R. Abbott, Time scales of pattern evolution from cross-spectrum analysis of advanced very high resolution radiometer and coastal zone color scanner imagery, J. Geophys. Res., 99, 7433-7442, 1994.

Fasham, M. J. R., and G. T. Evans, Advances in ecosystem modeling within JGOFS, in The Changing Ocean Carbon Cycle, edited by R. B. Hanson, H. W. Ducklow, and J. G. Field, pp. 417-446, Cambridge Univ. Press, New York, 2000.

Forristall, G. Z., K. J. Schaudt, and C. K. Cooper, Evolution and kinematics of a loop current eddy in the Gulf of Mexico, J. Geophys. Res., 97, 2173-2184, 1992.

Gilbes, F., C. Tomas, J. J. Walsh, and F. E . Muller-Karger, An episodic chlorophyll plume on the west Florida shelf, Cont. Shelf Res., 16, $1201-$ 1224, 1996.

Glenn, S. M., and C. C. Ebbesmeyer, Drifting buoy observations of a Loop Current anticyclonic eddy, J. Geophys. Res., 98, 20,105-20,119, 1993.

Gower, J. F. R., K. L. Denman, and R. J. Holyer, Phytoplankton patchiness indicates the fluctuation spectrum of mesoscale oceanic structures, Nature, 288, 157-159, 1980.

Haller, G., Finding finite-time invariant manifolds in two-dimensional velocity fields, Chaos, 10, 99-108, 2000.

Haller, G., Lagrangian coherent structures and the rate of strain in twodimensional turbulence, Phys. Fluids, 13, 3365-3385, 2001.

Haller, G., and A. C. Poje, Finite time transport in aperiodic flows, Physica $D, 119,352-380,1998$.

Hamilton, P., Lower continental slope cyclonic eddies in the central Gulf of Mexico, J. Geophys. Res., 97, 2185-2200, 1992.

Hamilton, P., G. S. Fargion, and D. C. Briggs, Loop current eddy paths in the western Gulf of Mexico, J. Phys. Oceanogr., 29, 1180-1207, 1999.

Hu, C., F. E. Müller-Karger, D. C. Biggs, K. L. Carder, B. Nababan, D. Nadeau, and J. Vanderbloemen, Comparison of ship and satellite bio-optical measurements on the continental margin of the NE Gulf of Mexico, Inter. J. Remote Sens, in press, 2003.

Indest, A. W., A. D. Kirwan Jr., J. K. Lewis, and P. Reinersman, A synopsis of mesoscale eddies in the Gulf of Mexico, in Mesoscale/Synoptic and Coherent Structures in Geophysical Turbulence, edited by J. C. J. Nihoul and B. M. Jamart, pp. 485-500, Elsevier Sci., New York, 1989.

Jones, C. K. R. T., and S. Winkler, Do invariant manifolds hold water? in Handbook of Dynamical Systems III: Towards Applications, edited by B. Fiedler, G. Iooss, and N. Kopell, Elsevier Sci., New York, 2000. Kantha, L. H., A general ecosystem model for applications to carbon cycling and primary productivity in the global oceans, Ocean Model, in press, 2003

Kantha, L. H., and C. A. Clayson, An improved mixed layer model for geophysical applications, J. Geophys. Res., 99, 25,235-25,266, 1994.

Kantha, L. H., J. K. Choi, R. Leben, C. Cooper, M. Vogel, and J. Feeney, Hindcasts and real-time nowcast/forecasts of currents in the Gulf of Mexico, paper presented at Offshore Technol. Conference, Offshore Technol., Houston, Tex., 3-6 May 1999.
Kirwan, A. D., Jr., Oceanic velocity gradients, J. Phys. Oceanogr., 5, 729735,1975

Kirwan, A. D., Jr., W. J. Merrell Jr., J. K. Lewis, and R. E. Whitaker, Lagrangian observations of an anticyclonic ring in the western Gulf of Mexico, J. Geophys. Res., 89, 3417-3424, 1984a.

Kirwan, A. D., Jr., W. J. Merrell Jr., J. K. Lewis, R. E. Whitaker, and R. Legeckis, A model for the analysis of drifter data with an application to a warm core ring in the Gulf of Mexico, J. Geophys. Res., 89, 3425-3438, 1984 b.

Kirwan, A. D., Jr., J. K. Lewis, A. W. Indest, P. Reinersman, and I. Quintero, Observed and simulated kinematic properties of loop current rings, J. Geophys. Res., 93, 1189-1198, 1988.

Kirwan, A. D., Jr., M. Toner, and L. Kantha, Predictability, uncertainty, and hyperbolicity in the ocean, Int. J. Eng., 249-258, 2003.

Koh, T.-Y., and R. A. Plumb, Lobe dynamics applied to barotropic Rossbywave breaking, Phys. Fluids, 12, 1518-1528, 2000.

Kuznetsov, L., M. Toner, A. D. Kirwan, C. K. R. T. Jones, L. Kantha, and J. Choi, The Loop Current and adjacent rings delineated by Lagrangian analysis of the near surface flow, J. Mar. Res, 60, 405-429, 2002.

Lapeyre, G., B. L. Hua, and B. Lagras, Comment on "Finding finite-time invariant manifolds in two-dimensional velocity fields", Chaos, 11, 427430, 2001

Leben, R. R., and G. H. Born, Tracking Loop Current eddies with satellite altimetry, Adv. Space Res., 13, 325-333, 1993.

Lewis, J. K., and A. D. Kirwan Jr., Genesis of a Gulf of Mexico ring as determined from kinematic analysis, J. Geophys. Res., 92, 11,727$11,740,1987$.

Lewis, J. K., A. D. Kirwan Jr., and G. Z. Forristall, Evolution of a warmcore ring in the Gulf of Mexico: Lagrangian observations, J. Geophys. Res., 94, 8163-8178, 1989

Loder, J. W., Y. Shen, and H. Ridderinkhof, Characterization of threedimensional Lagrangian circulation associated with tidal rectification over the submarine bank, J. Phys. Oceanogr., 27, 1729-1742, 1997.

Longhurst, A., Seasonal cooling and blooming in tropical oceans, Deep Sea Res., 40, 2145-2165, 1993.

Lopez, J. W., and L. H. Kantha, A data-assimilative numerical model of the North Indian Ocean, J. Atmos. Ocean. Tech., 17, 1525-1540, 2000

MacKay, R. S., J. D. Meiss, and I. C. Percival, Transport in Hamiltonian systems, Physica D, 13, 55-81, 1984.

Martin, A. P., On filament width in oceanic plankton distributions, J. Plank. Res., 22, 597-602, 2000 .

Miller, P. D., C. K. R. T. Jones, A. M. Rogerson, and L. J. Pratt, Quantifying transport in numerically generated velocity fields, Physica D, 101, $105-122,1997$

Miller, P. D., L. J. Pratt, K. R. Helfrich, and C. K. R. T. Jones, Chaotic transport of mass and potential vorticity for an island recirculation, J. Phys. Oceanogr., 32, 80-102, 2002.

Mellor, G. L., and T. Yamada, Development of a turbulence closure model for geophysical fluid problems, Rev. Geophys., 20, 851-875, 1982.

Merrell, W. J., and J. M. Morrison, On the circulation in the western Gulf of Mexico with observations from April 1978, J. Geophys. Res., 86, $4181-$ 4185, 1981.

Merrell, W. J., and A. M. Vasquez, Observations of changing mesoscale circulation patterns in the western Gulf of Mexico, J. Geophys. Res., 88, $7721-7723,1983$.

Müller-Karger, F. E., J. J. Walsh, R. H. Evans, and M. B. Meyers, On the seasonal phytoplankton concentration and sea surface temperature cycles of the Gulf of Mexico as determined by satellites, J. Geophys. Res., 96 , $12,645-12,665,1991$

Ogden, J. C., Marine managers look upstream for connections, Science, 278, 1414-1415, 1997

Ohlmann, J. C., P. P. Niiler, C. A. Fox, and R. R. Leben, Eddy energy and shelf interactions in the Gulf of Mexico, J. Geophys. Res., 106, 26052620, 2001.

Perez, R., F. E. Muller-Karger, I. Victoria, N. Melo, and S. Cerdeira, Cuban, Mexican, U.S. researchers probing mysteries of Yucatan Current, Eos Trans. $A G U, 80,14,153,1999$

Pierrehumbert, R. T., Large-scale horizontal mixing in planetary-atmospheres, Phys. Fluids A, 3, 1250-1260, 1991.

Poje, A. C., and G. Haller, Geometry of cross-stream mixing in a doublegyre ocean model, J. Phys. Oceanogr., 29, 1649-1665, 1999.

Ridderinkhof, H., and J. W. Loder, Lagrangian characterization of circulation over submarine banks with application to the outer Gulf of Maine, J. Phys. Ocenogr., 24, 1184-1200, 1994.

Roberts, C. M., Connectivity and management of Caribbean coral reefs, Science, 278, 1454-1457, 1997.

Rogerson, A. M., P. D. Miller, L. J. Pratt, and C. K. R. T. Jones, Lagrangian motion and fluid exchange in a barotropic meandering jet, J. Phys. Oceanogr. 29, 2635-2655, 1999. 
Rom-Kedar, V., A. Leonard, and S. Wiggins, An analytical study of transport, mixing and chaos in an unsteady vortical flow, J. Fluid Mech., 214, 347-394, 1990.

Schaudt, K. J., et al., A look at currents in the Gulf of Mexico in 19992000, paper presented at Offshore Technology Conference (OTC01), sponsor?, location?, 2001.

Toner, M., A. D. Kirwan Jr., L. Kantha, and J. Choi, Can general circulation models be assessed and their output enhanced with drifter data?, J. Geophys. Res., 106, 19,563-19,579, 2001.

Vidal, V. M. V., F. V. Vidal, A. F. Hernádez, E. Meza, and J. M. PérezMolero, Baroclinic flows, transports, and kinematic properties in a cyclonic-anticyclonic ring triad in the Gulf of Mexico, J. Geophys. Res., 99, 7571-7597, 1994.

Vukovich, F. M., and B. W. Crissman, Aspects of warm rings in the Gulf of Mexico, J. Geophys. Res., 91, 2645-2660, 1986.

Woods, J. D., Mesoscale upwelling and primary production, in Towards a Theory of Biological-Physical Interactions in the World Ocean, edited by B. J. Rothschild, Kluwer Acad., Norwell, Mass., 1988.
Wroblewski, J. S., J. J. O’Brien, and T. Platt, On the physical and biological scales of phytoplankton patchiness in the ocean, Memoires Soc. Royale des Sci. de Liege, 6, 43-57, 1975.

M. Toner and A. D. Kirwan Jr., College of Marine Studies, University of Delaware, Robinson Hall, Newark, DE 19716-3501, USA. (toner@udel. edu; adk@udel.edu)

A. C. Poje, Department of Mathematics, Building 1S-215, College of Staten Island, 2800 Victory Blvd., Staten Island, NY 10314, USA. (poje@math.csi.cuny.edu)

L. H. Kantha, Colorado Center for Astrodynamics Research, University of Colorado, Boulder, CO, USA. (kantha@colorado.edu)

F. E. Müller-Karger, Department of Marine Science, University of South Florida, 104 7th Ave. South, St. Petersburg, FL 33701, USA. (carib@) seas.marine.usf.edu)

C. K. R. T. Jones, Department of Mathematics, Phillips Hall, University of North Carolina, Chapel Hill, NC 27599, USA. (ckrtj@math.unc.edu) 